\title{
Seismic analysis of lateral force resisting steel frame with honeycombed steel thin plate shear wall
}

\author{
Muhammad Akbar ${ }^{1}$, Assad Ali², Pan Huali ${ }^{3}$, Muhammad Mohsin ${ }^{4}$, Ou Guoqiang 5 , \\ Amin Azka ${ }^{6}$, Hazrat Yousaf ${ }^{7}$ \\ ${ }_{1,3,5}$ Department of Engineering Institute of Mountain Hazards and Environment, Chinese Academy of \\ Science, Chengdu, China \\ ${ }^{1,3,5}$ Department of Civil Engineering Sir Syed University of Engineering and Technology, Karachi, \\ Pakistan \\ ${ }^{2,4}$ School of Architecture and Civil Engineering, Jiangsu University Science and Technology, Jiangsu, \\ China \\ ${ }^{6}$ School Management Iqra University, Karachi, Pakistan \\ ${ }^{7}$ School Management lasbela University, Uthal, Balochistan, Pakistan \\ ${ }^{2}$ Corresponding author \\ E-mail: ${ }^{1}$ akbarmohammad0092@mails.ucas.ac.cn, ${ }^{2}$ assadali0041@gmail.com, ${ }^{3}$ phl0902@126.com, \\ 4Akbarmohammad0092@gmail.com, ${ }^{5}$ ougq@imde.ac.cn, ${ }^{6}$ azkz.amin@iqra.edu.pk, \\ 7dr.yousaf@luawms.edu.pk
}

Received 8 August 2021; received in revised form 21 September 2021; accepted 2 October 2021 DOI https://doi.org/10.21595/jve.2021.22171

Check for updates

Copyright $(2021$ Muhammad Akbar, et al. This is an open access article distributed under the Creative Commons Attribution License, which permits unrestricted use, distribution, and reproduction in any medium, provided the original work is properly cited.

\begin{abstract}
In high-rise buildings, shear walls are an important structures feature for sustaining lateral forces. The production of prefabricated steel frames buildings will effectively overcome iron and steel spare capacity, allowing the building sector to recover the industrial revolution. As an advanced kind of flexural rigidity steel plate shear walls (SPSWs) can withstand majority of the load in the frame structure, boost the preliminary lateral toughness and lateral bearing strength, and serve as a first protective barrier until the main frame is demolished, reducing the main frame's failure level and improving the structure's failure resistance. When structures are subjected to external loads such as earthquakes, wind, and other natural disasters, shear walls can be used to increase the structure's strength and safety. The main focus of this research is to use SAP2000 to compare and analyze two different types of shear walls in two different 7-story buildings. Two structural members, one having a honeycombed steel sheet sandwiched between two thin steel plates shear wall and the other having RCC shear wall are compared based on lateral loading parameters (base shear, displacement story-drift etc.). Using SAP2000, the effects of three main parameters were investigated by Pushover analysis and Time history analysis. From the complete analysis, shear wall with honey combed thin plates is proved to be better against seismic and wind loading as compared to RCC wall as well as honeycombed sheet sandwiched between steel plates is economical and gives more area to the story by occupying less space.
\end{abstract}

Keywords: steel structures, honeycombed steel, SAP2000, finite element analysis, shear wall.

\section{Introduction}

The use of SPSWs to improve the lateral stability of concrete structures was addressed in this experimental as well as analytical study is done in ABAQUS models were used to study the analytical portion. The result showed that as compared to the system model, the SPSW-applied versions have a horizontal loadbearing capability of 7.5 to 2.7 times. The use of SPSW improves the rigidity of the structural element greatly. The SPSW installation in the systems would also reduce the buildings values of inter-story drift and increases in horizontal load-bearing capability and strength of RC frames significantly [1].

The behavior of Honey combed composite structures. The bending moment of honey combed composite sandwich plate the low tensile strength and stiffness, torsional-strength etc. are all advantages of bio composites (fibers). Textile and polypropylene fibers are used as reinforcement, 
general purpose silicone is used as a layer, and coco fiber pith and saw dust are used as filler particles. It has been determined that a composite plate loaded with saw dust can tolerate a peak load of 16.71 percent and a splitting load of 16.71 percent [2]

Moment-resistant and pinned beam-to-column ties were used on the steel plate shear walls. Moreover, cycling loading test was done on a pair of specimens. For the infill plates and boundary frames, LYS and HYS steel was used. The specimens had strong stiffness and excellent ductility and the effect of rigid and pinned beam-column connections on strength, efficiency and overall energy dissipation [3]. the study revealed that structures with shear walls had lower lateral load displacements and bending moments than structures [4].

The characteristics of shear wall by the different kind of connections used the non-linear analysis to investigate the change in RC frame structure by using different kinds of connection. Four connection forms for shifting tension field forces between SPSW and RC frames. The results showed that the through use of SPSW in RC frames with reasonable connections could provide excellent ductility and strong load carrying capability [5].

Seismic analysis of SPSW response for multiple steel plate and RC shear wall sizes. The software used in the research are ETABS (2013 version) and SAP2000. Structure modelling of 4 models is done on this software. For construction analysis, static and dynamic analysis approaches are used. Steel plates of varying depth $(5 \mathrm{~mm}$ and $10 \mathrm{~mm})$, composite steel parts, RC walls, and steel bracing are used in the building model. Under pin and fixed support conditions, the action of a building with and without a SPSW is investigated. From overall modelling steel plate of with $5 \mathrm{~mm}$ has shown results [6]. The SPSW developed large in and out plane displacements that reduced as plate thickness increased; singly stiffened followed by doubly stiffened SPSW produced lower in and out- plane displacements. The displacement values reduced by one percent, until three percent when doubly stiffened, with the inclusion of stiffeners in SPS steel walls. On the other hand, the out of plane displacement values decreased by fifty percent when stiffened singly and even when doubly -stiffened. The plate bending analysis done on a panel with various loading conditions to verify the validity. It's worth noting that perhaps the stiffener has little impact on any of the criteria except out of plane movement. There was no critical portion for the 12 and 16 plate shear walls, and maximum displacement was found to be 0.0744 and 0.070 millimeters, accordingly $[7,8]$.

According to the American design codes of year 2005, shear plate shear wall is a latest and advanced member that has been introduced in the world of civil engineering. Shear plate - shear wall has a connecting stud. An analytical relationship is suggested for measuring the CSPSW's ultimate power, which will aid in the design and study of this new axial forces bearing framework. Moreover, the results showed that the new system is quite effective. Less buckling is observed in the steel of the structure [9]. The finite element model of a 6 story, three spans RCF building was created using SAP-2000. The corrosion rate rises, the inter-story drift ratios rise sharply as well. But the rise depends greatly on where the stories are located. Deformation of the building can occur easily if it is subjected to an earthquake of higher magnitude if the bars are corroded [9].

The shear force distribution of a multi-story reinforced concrete frame with steel shear walls is evaluated. In the case of $T_{p} / T_{1}=1$, the maximum displacement and force requirements of different structures are obtained. At the same time, as the number of stories increases, the influence of higher modes reduced, and the structure tends to fluctuate in the first mode. [11]. In order to consider the influence of the earthquake on $R \mu$, the far-field and near-field vibrations of the reinforced concrete frame and the steel plate shear wall were compared. The results show that the $R \mu$ corresponding to near-field and far-field vibrations may be different. In addition, CR does not depend on the type of earthquake, and converges to 1 as the vibration period increases [12]. Evaluate the efficiency of advanced nonlinear static analysis to assess the seismic demand of high-rise buildings, using SPSW as a lateral resistance system affected by higher modes [13].

SPSW had more benefits for lateral load resistance systems than traditional lateral load resisting systems used for seismic resistance design of structures due to robust post-buckling 
capability, a high degree of ductility, stable hysteretic properties, and high value of stiffness as compared to conventional resisting systems [13]. Sandwich panels have a quite good strength and a low weight as compared to standard panels. Shear stress (depends upon angle and load of application) primarily applied to the center of these frameworks and numerical calculations are used to investigate the transmission and degree of shear stresses [14].

The work is carried out the s analysis of finite element and SAP-2000 process. Shear walls give resistance against lateral loading. 4 distinct systems are used to assess the output of RCC shear wall construction. Seismic shear walls' properties control the building's responsiveness, so it's crucial to assess the walls' dynamic performance properly. G+10 storey buildings in various areas are subjected to an earthquake load. The building's output is measured by the lateral displacements of every story building $[15,16]$.

The purpose of this research is to assess the behavior of $\mathrm{G}+7$ story building with honey-combed sandwiched between thin steel plates as a shear wall. The main purpose is to investigate the behavior and strength of this sandwiched honey-combed shear wall in RC structure against wind and earthquake loads busing finite element analysis busing SAP2000.

\section{Methodology}

The methodology of this project is characterized by a number of design combinations needed which are used in the software named as "CSI SAP 2000". The type of analysis used in this project is "Non-Linear Static Analysis" and "Time History Analysis". This research consists of three models [17]. The steel frames were designed according to the guidelines as stated in the Chinese code for the standard for design of steel structures GB50017-2017 [18].

\subsection{Structural modeling}

All the beam members and column members are drafted in SAP2000 for the two models. The loads and properties were assigned in the SAP2000. Analysis had been done on the building and then results of the cases was compared and concluded. The dimension of the buildings is show in Figs. 1 and 2.

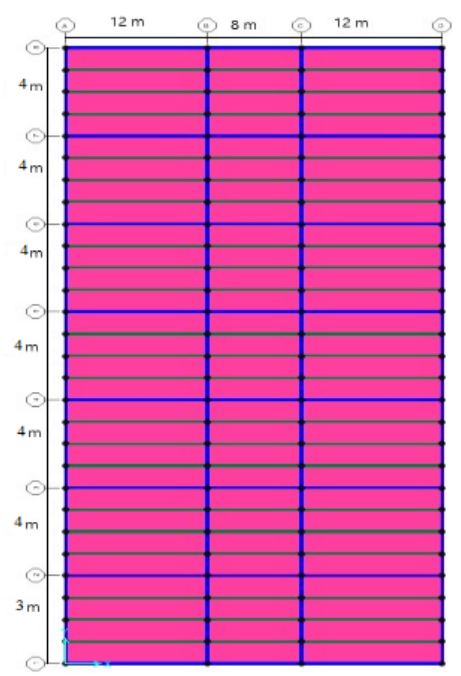

Fig. 1. Dimensional plan of building. Height of the very first story is $3 \mathrm{~m}$. Height of the other remaining stories is $4 \mathrm{~m}$. Overall area of building is $2240 \mathrm{~m}^{2}$. Thickness of floor $t=40 \mathrm{~mm}$ 


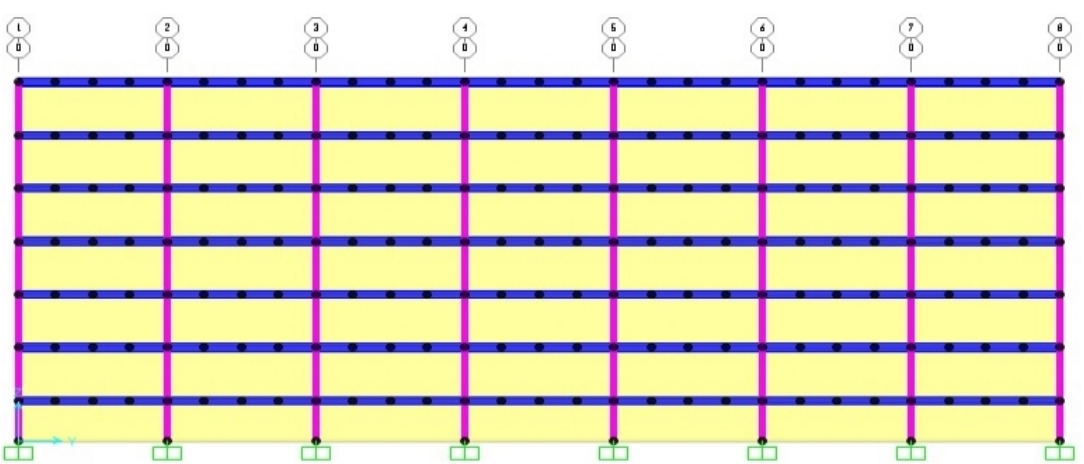

Fig. 2. Elevation of the building

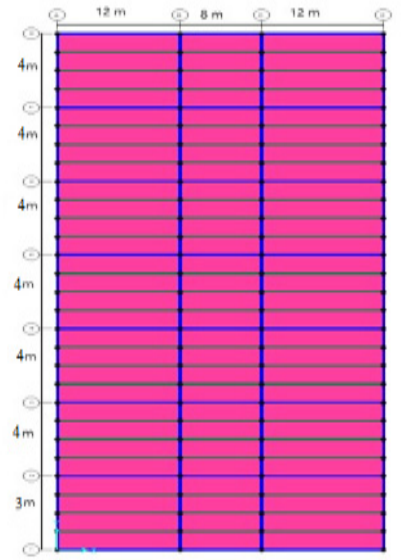

a)

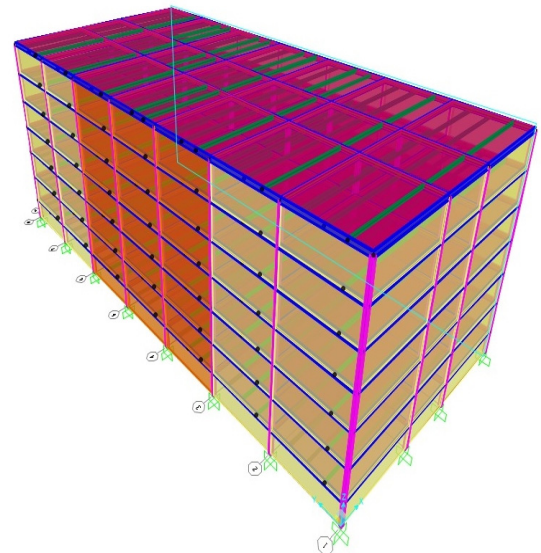

b)

Fig. 3. 3D Model of building

\section{BUILDING period}

Analyses or formulae based on empirical evidence can be used to calculate the construction period $T$. If it's determined by empirical formulae, it's referred to as $T_{A}$, and if it's determined by analysis, it's referred to as TB. For all framing systems, the single empirical formula shown below can be employed:

$T_{A}=C_{t} h^{\frac{3}{4}}$

where, value of $C_{t}$, for frames with steel moment -0.035 , for frames with concrete moment 0.030 , for the frames with eccentric bracing -0.030 , for other building $-0.020, h$ is total pinnacle of structure $\left(f_{t}\right)$.

\section{Materials properties and elements of building}

The mechanical properties of the materials used for this building are show in Table 1:

- Compressive strength of concrete, $f_{c}^{\prime}=20 \mathrm{MPa}(\mathrm{C} 20)$.

- The grade of Steel Q345B.

In this research, using Finite Element Model (FEM) mechanical properties of honeycombed Nomex ${ }^{R}$ are determined. This model was update as per accordance to out of plan shear modulus [14]. The mechanical properties of honeycomb structures are orthotropic, meaning that their values alter when the introduction of the stretch with regard to the fabric changes. Subsequently, 
the two planes of symmetry must be distinguished and recognized. The L-direction is the most grounded course, and the W-direction (found 60 from the L-direction in the event that the honeycomb may be a customary hexagon) is the foremost compliant course.

$\mathrm{RC}$ shear dividers give expansive quality and stiffness to buildings within the heading of their orientation, which essentially decreases horizontal sway of the building and in this manner diminishes harm to structure and its substance. Since shear dividers carry large even seismic tremor strengths, the overturning effects on them are huge. Shear dividers in buildings must be symmetrically found in arrangement to diminish ill effects of twist in buildings. They may be placed symmetrically along one or both bearings in plan. Shear dividers are more viable when found along the outside border of the building; such a layout increases resistance of the building to bending.

Table 1. 3D mechanical properties of honeycombed sheet for densities of $64 \mathrm{~kg} / \mathrm{m}^{3}$ and 29,48 sheet

\begin{tabular}{|c|c|c|c|c|c|c|}
\hline ECA-R & Minimum & Typical & Minimum & Typical & Minimum & Typical \\
\hline MPa & $4.8-29(51)$ & $4.8-29(51)$ & $4.8-48(51)$ & $4.8-48(51)$ & $4.8-64(51)$ & $4.8-64(51)$ \\
\hline V12 & \multicolumn{2}{|c|}{0.2606} & \multicolumn{2}{c|}{0.2606} & \multicolumn{2}{c|}{0.2606} \\
\hline V13 & \multicolumn{2}{|c|}{0.2240} & \multicolumn{2}{c|}{0.2240} & \multicolumn{2}{c|}{0.2240} \\
\hline V23 & \multicolumn{2}{|c|}{0.0219} & \multicolumn{2}{c|}{0.0219} & \multicolumn{2}{c|}{0.0219} \\
\hline E1 & 44.5 & 72.5 & 101.1 & 128.7 & 129.6 & 152.0 \\
\hline E2 & 4.4 & 7.1 & 9.9 & 12.6 & 12.7 & 14.9 \\
\hline E3 & 79.4 & 129.5 & 180.5 & 229.8 & 231.4 & 271.5 \\
\hline G12 & 0.5 & 0.9 & 1.2 & 1.6 & 1.6 & 1.9 \\
\hline G13 W & 14.6 & 23.9 & 33.3 & 42.4 & 42.7 & 50.1 \\
\hline G23 L & 8.6 & 14.1 & 19.6 & 25.0 & 25.1 & 29.5 \\
\hline
\end{tabular}

The insight of the modeling was used for several various frame components are given below in this section.

Table 2. The section used for beams and columns was W-section.

\begin{tabular}{|c|c|c|}
\hline Main beam Q345B & Vertical beam Q345B & Column segment Q345B \\
\hline $800 \times 200 \times 8 \times 13$ & $800 \times 200 \times 8 \times 13$ & $400 \times 400 \times 200 \times 200$ \\
\hline
\end{tabular}

\section{Results}

In this research, honeycombed steel sheet sandwiched between two thin steel plates is analyzed and compared with RCC shear walls. The 7-storey building is situated in Jashi, China. The zone of this city is 7. The earthquake data used for analysis is of magnitude 5.8. At first steel structure with RCC shear wall is compared with steel frame with honeycombed sheet of steel sandwiched between two shear walls of thin steel plate. Analysis is compared to investigate the base shear and monitor displacement through pushover analysis and time period of the building by time history analysis. Analyses are performed with SAP2000.

\subsection{Pushover graphs in X-direction}

This result is plotted between Base shear $(\mathrm{KN})$ and Displacement $(\mathrm{m})$ of building having RCC shear wall. The results are of pushover analysis in $X$-direction. Graph shows linearity by straight inclined line. The maximum value of base shear is $422684.9 \mathrm{KN}$ and max displacement is $9.29 \mathrm{E}+00$.

The result is honeycombed shear wall building with max base shear $2033080 \mathrm{KN}$ and max displacement $8.34 \mathrm{E}-05 \mathrm{~m}$. The Base Shear Capacity is around 2033080 at the point where the curve shows reversal of displacement in the graph. This reversal of curve shows the positive backward displacement. The building switches from the plastic behavior to elastic behavior. 
SEISMIC ANALYSIS OF LATERAL FORCE RESISTING STEEL FRAME WITH HONEYCOMBED STEEL THIN PLATE SHEAR WALL. Muhammad Akbar, Assad Ali, Pan Huali, Muhammad Mohsin, Ou Guogiang, Amin AZKa, Hazrat Yousaf

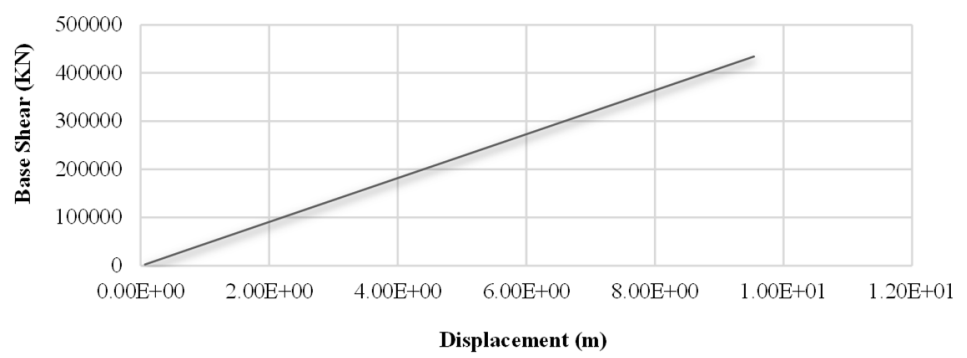

Fig. 4. Graph base shear vs displacement of RCC SW building $X$-direction

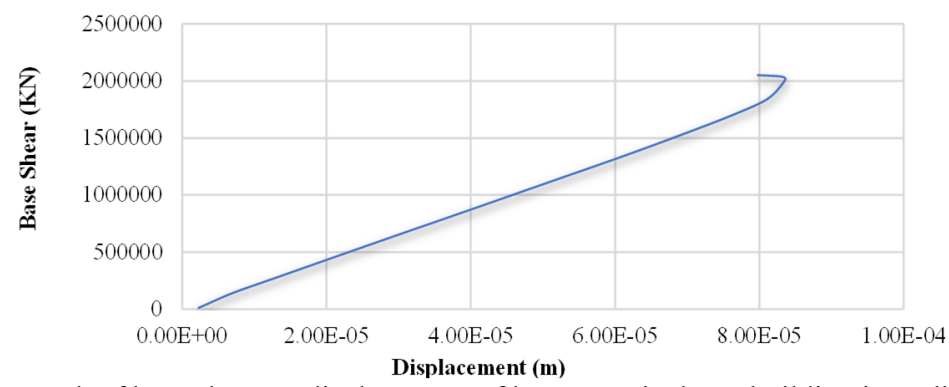

Fig. 5. Graph of base shear vs displacement of honeycombed SW building in $X$-direction

\subsection{Pushover graphs in Y-direction}

The results show that relation between base shear $(\mathrm{KN})$ and displacement $(\mathrm{m})$ of building having RCC shear wall. The results are of pushover analysis in $X$-direction. The maximum value of base shear is $52115590 \mathrm{KN}$ and max displacement is $2.73 \mathrm{E}+01$. Up to some extent as the base shear is increasing, displacement remains the almost same. But after this both increase. And after this phase with small increase in base shear, displacement increases very rapidly till the maximum value.

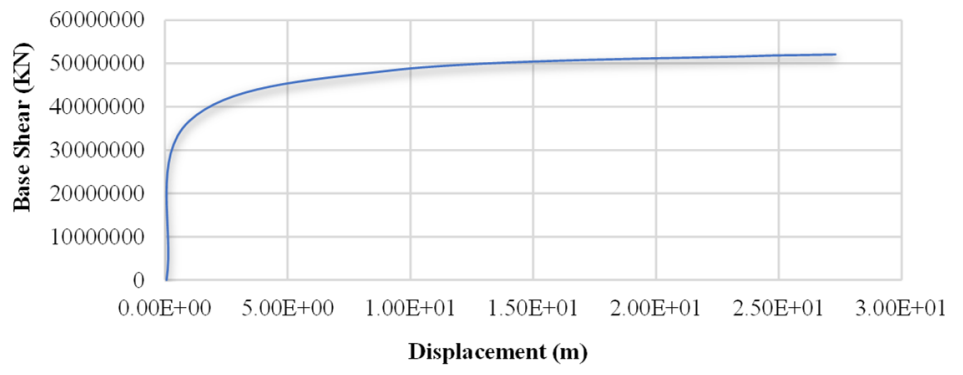

Fig. 6. Graph of base shear vs displacement of RCC SW building in $Y$-direction

Similarly, in the $y$-direction the above-mentioned phenomenon repeats itself. The Base Shear Capacity is around 2050000 at the point where the curve shows reversal of displacement in the graph. This reversal of curve shows the positive backward displacement in $y$-direction. The Honeycombed SW Building switches from the plastic behavior to elastic behavior.

\subsection{Time history graphs in $\mathrm{X}$-direction}

The graphical results of study show that relationship between inter-story drift and base shear for RCC shear wall building. In the first portion, as the base shear increases inter-story drift remains constant for some time. In middle, inter story drift increases with fluctuations with 
increase in base shear and at last again base shear increases but drift remains constant.

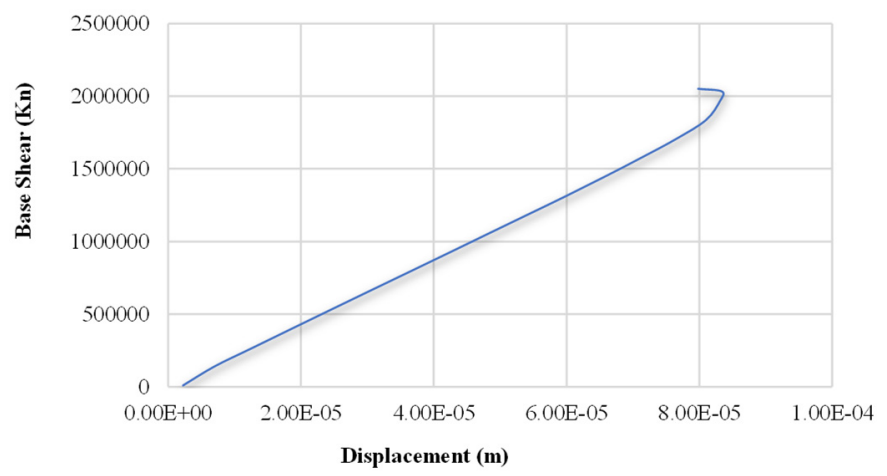

Fig. 7. Graph of base shear vs displacement of honeycombed SW building in $Y$-direction

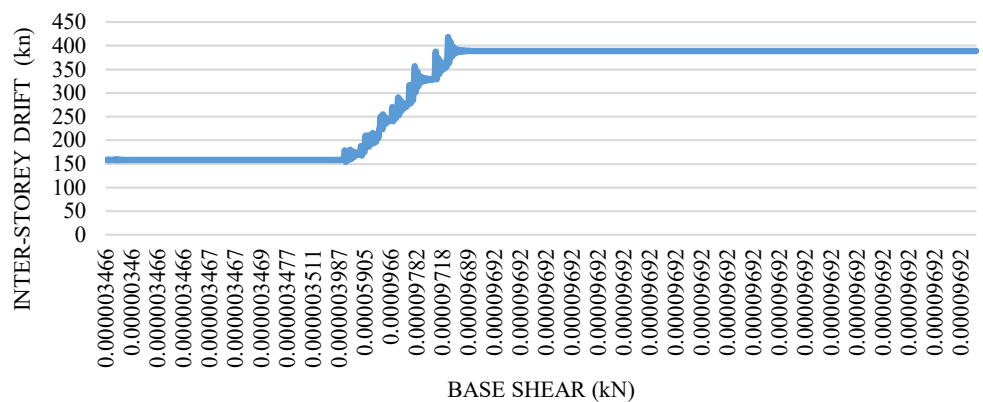

Fig. 8. Graph of inter story drift vs base shear of building with RCC SW

This graph shows the relation between inter-story drift and base shear for honey combed shear wall building. In the first portion, as the base shear increases inter-story drift fluctuates very rapidly and these fluctuations reduces as base shear increases further. After this graph becomes horizontal.

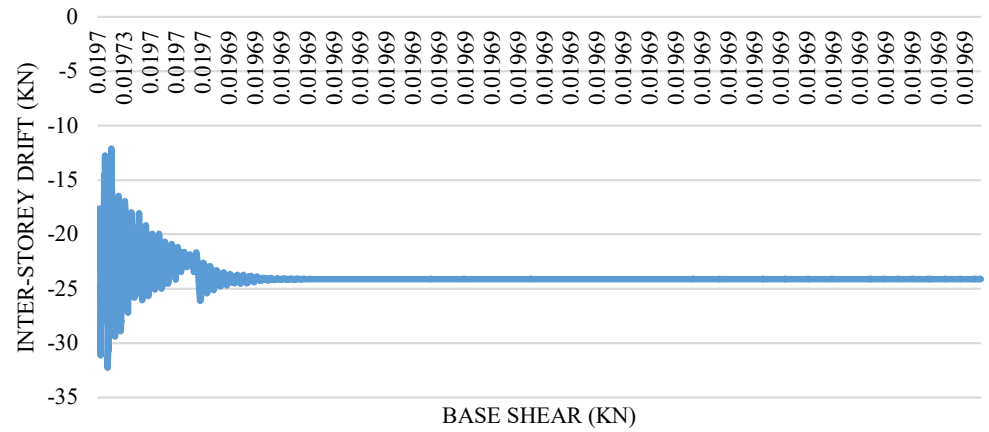

Fig. 9. Graph of inter story drift vs base shear of building with honeycombed SW

\subsection{Time history graphs in Y-direction}

This graph shows the relation between inter-story drift and base shear for RCC shear wall building. In the first portion, as the base shear increases inter-story drift remains constant for some time. In middle, inter story drift increases with fluctuations with increase in base shear and at last again base shear increases but drift remains constant.

This graph shows the relation between inter-story drift and base shear for honey combed shear 
wall building. In the first portion, as the base shear increases inter-story drift fluctuates a little and these fluctuations reduces as base shear increases further. After some time the fluctuations in inter story drift increases and this goes on happening further.

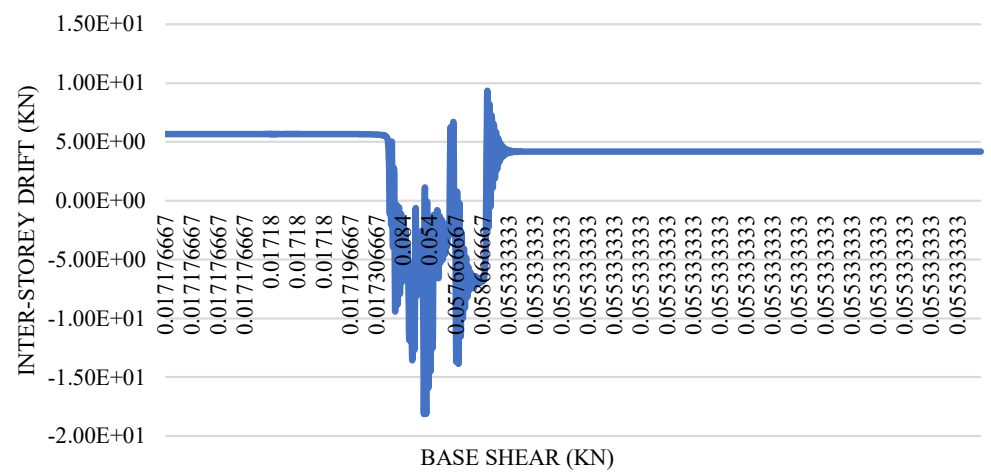

Fig. 10. Graph of inter story drift vs base shear of RCC SW building in $Y$-direction

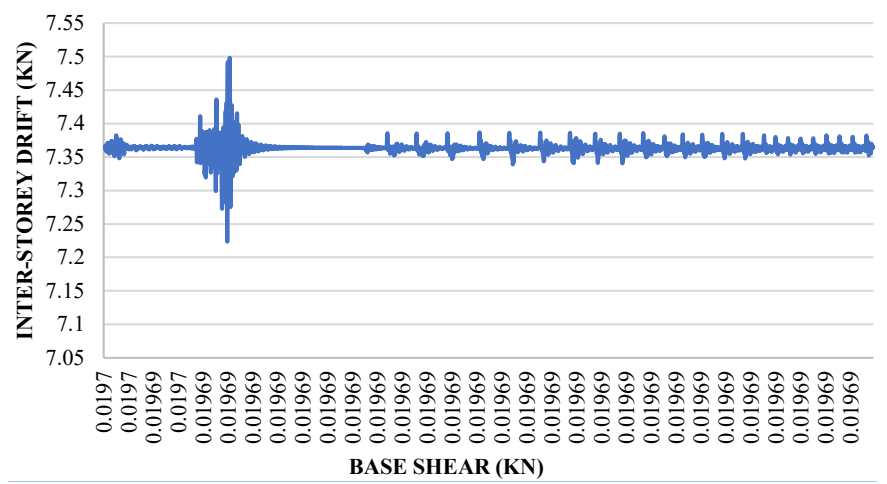

Fig. 11. Graph of inter story drift vs base shear of building with honeycombed SW in $Y$-direction

\subsection{Response spectrum curves}

The seismic responses of the building (Building with Honeycombed SW) for distribution of story displacement and inter-story drift are shown in the figures below. These graphs show the relation between Story displacement distribution and the time period for honey combed shear wall building, floor wise. From the results it is conclude that the honey combed shear wall building story displacement distribution of lower floors was similar to that of upper floors.

From the results it is conclude that the reinforcement share wall building story displacement distribution of lower floors was not similar to that of upper floors we can see the displacement distribution of floor not same.

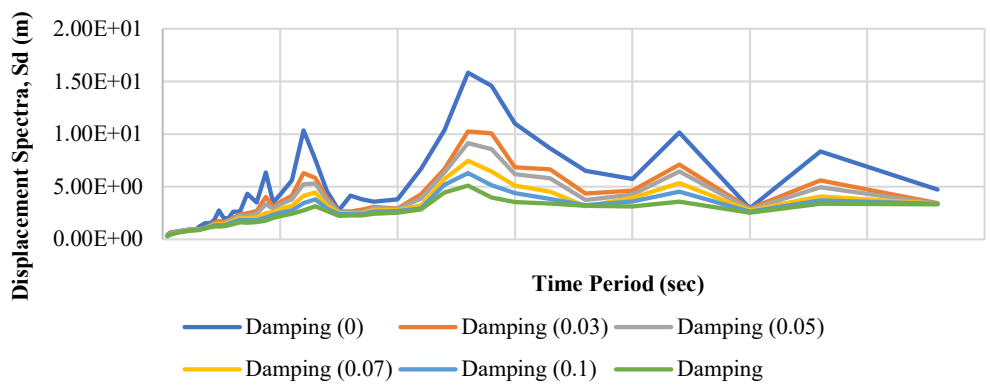

Fig. 12. Response spectrum curve at honey combed shear wall 1st floor to 7Th floor 


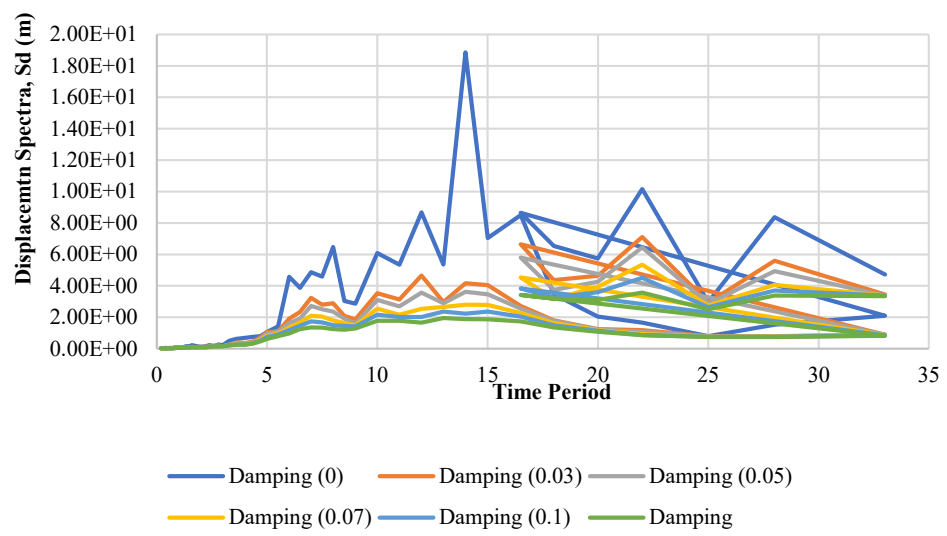

Fig. 13. Response spectrum curve at reinforcement share wall 1st Floor to 7Th floor

\section{Conclusions}

In this study, honeycombed steel sheet sandwiched between two thin steel plates is analyzed and compared with RCC shear walls. Analysis is compared with to investigate the base shear and monitor displacement through pushover analysis and time period of the building by time history analysis. Analyses are performed with software called SAP2000. The results of the analytical research presented in this thesis showed that the structure with honeycombed steel sheet is more stable to lateral loading than the one having RCC shear walls. From behavior of the building throughout analysis, subsequent conclusions were created.

From the results it's concluded that:

1) It is clearly observed that displacement of honeycombed steel sheet sandwiched between two thin steel plates is lesser in comparison to RCC shear wall structure.

2) At base shear around $270 \mathrm{KN}$, displacement ( $x$-direction) in honeycombed steel sheet' structure is around $3.6 \times 10^{-6} \mathrm{~mm}$ whereas displacement in RCC shear wall's structure is around $5.88 \mathrm{~mm}$.

3) The results of $Y$ direction's displacement concluded that negligible displacement occurs in a structure with honey-combed thin plate sandwiched in shear wall, when it is exposed to lateral loads.

4) The study and also its result also revealed that the installation of honeycombed systems would also reduce the buildings inter story drifting values and increases the horizontal load-bearing capability as compared to the structure having RCC shear wall.

5) The installation of honeycombed systems would also reduce the cost of the building, because honeycombed thin plates are cheaper than normal steel shear plates, makes building more economical.

6) The base shear capacity is around 2050000 in the graphs of base shear vs displacement of honeycombed SW building in $X$-direction and $Y$-direction showing $x$ and $y$ displacement of honey at the point where the curve shows reversal of displacement in the graph. This reversal in the curve basically shows the positive backward displacement. The building switches from the plastic behavior to elastic behavior.

Policy recommendation and research scope. Since there aren't many researches on the honeycombed thin plate shear wall, this thing being lightweight (economical), having more ductility and resistance to lateral loading than RC Shear wall can proved to be a great innovation in the field of structural engineering. Use of steel in construction industry is very advantageous as it is less expensive, stiffer and durable. Waste steel after recycling can also be used for this purpose. Shear walls made of steel have been used worldwide due to its better performance against lateral loads. Honey-combed steel plate shear walls are light weight and they can be used as lateral loads resisting devices if they are analyzed and used properly. After doing this study, we will be 
able to tell that how much they can resist loads and make the structure economical and durable. However, there is still a lot of place where a lot better research is needed. For example, research can be done on buildings with $10+$ stories with a vast area, having different zones.

\section{Policy Recommendation and Research Scope}

Since there aren't many research on the honeycombed thin plate shear wall, this thing being lightweight (economical), having more ductility and resistance to lateral loading than RC Shear wall can proved to be a great innovation in the field of structural engineering.

Use of steel in construction industry is very advantageous as it is less expensive, stiffer and durable. Waste steel after recycling can also be used for this purpose. Shear walls made of steel have been used worldwide due to its better performance against lateral loads. Honey-combed steel plate shear walls are light weight, and they can be used as lateral loads resisting devices if they are analyzed and used properly. After doing this study, we will be able to tell that how much they can resist loads and make the structure economical and durable.

However, there is still a lot of places where a lot better research is needed. For example, research can be done on buildings with $10+$ stories with a vast area, having different zones.

\section{Acknowledgements}

This paper was supported by the Second Tibetan Plateau Scientific Expedition and Re359 search Program (STEP), (Grant No. 2019QZKK0902) and National Natural Science Foundation of 360 China (Grant No. 42077275). It was also supported by Youth Innovation Promotion Association of 361 the Chinese Academy of Sciences (2018405).

\section{References}

[1] M. Gorji Azandariani, M. Gholhaki, and M. A. Kafi, "Experimental and numerical investigation of low-yield-strength (LYS) steel plate shear walls under cyclic loading," Engineering Structures, Vol. 203, p. 109866, Jan. 2020, https://doi.org/10.1016/j.engstruct.2019.109866

[2] J. W. Berman and M. Bruneau, "Experimental investigation of light-gauge steel plate shear walls," Journal of Structural Engineering, Vol. 131, No. 2, pp. 259-267, Feb. 2005, https://doi.org/10.1061/(asce)0733-9445(2005)131:2(259)

[3] A. K. Bhowmick, "Seismic behavior of steel plate shear walls with centrally placed circular perforations," Thin-Walled Structures, Vol. 75, pp. 30-42, Feb. 2014, https://doi.org/10.1016/j.tws.2013.09.027

[4] P. Chandurkar and D. P. Pajgade, "Seismic analysis of RCC building with and without shear wall," International Journal of Modern Engineering Research, Vol. 3, No. 3, pp. 1805-1810, 2013.

[5] V. S. Damam, "Comparative Study on Multistoried RCC Structure with and without Shear Wall by using SAP2000 v17," Unpublished, Vol. 2, No. 7, p. 2000, 2015, https://doi.org/10.13140/rg.2.2.35613.51688

[6] O. Esmaili, S. Epackachi, M. Samadzad, and S. R. Mirghaderi, "Study of structural RC shear wall system in a 56-story RC tall building," in 14th World Conference on Earthquake Engineering, Jun. 2014.

[7] M. Meghdadaian and M. Ghalehnovi, "Improving seismic performance of composite steel plate shear walls containing openings," Journal of Building Engineering, Vol. 21, pp. 336-342, Jan. 2019, https://doi.org/10.1016/j.jobe.2018.11.001

[8] R. M. Phuke, "Behaviour of multi-storeyed steel building with steel plate shear wall," International Journal for Research in Applied Science and Engineering Technology, Vol. 9, No. VIII, pp. 518-530, Aug. 2021, https://doi.org/10.22214/ijraset.2021.37357

[9] A. Astaneh Asl and X. Qian, "Development of a high-performance steel plate shear wall system," International Journal of Earthquake and Impact Engineering, Vol. 1, No. 1/2, p. 57, 2016, https://doi.org/10.1504/ijeie.2016.10000970

[10] S. R. Salimbahrami and M. Gholhaki, "Analytical study to evaluate the effect of higher modes of reinforced concrete moment-resisting frames with thin steel shear wall under simple pulse," Advances 
in Structural Engineering, Vol. 21, No. 15, pp. 2311-2325, Nov. 2018, https://doi.org/10.1177/1369433218773241

[11] S. Reza Salimbahrami and M. Gholhaki, "Effects of higher modes and degrees of freedom (DOF) on strength reduction factor in reinforced concrete frames equipped with steel plate shear wall," Structures, Vol. 19, pp. 234-247, Jun. 2019, https://doi.org/10.1016/j.istruc.2019.01.015

[12] S. R. Salimbahrami and M. Gholhaki, "Evaluation of seismic demands of reinforced concrete frames with steel plate shear wall," Proceedings of the Institution of Civil Engineers - Structures and Buildings, pp. 1-16, Jan. 2021, https://doi.org/10.1680/jstbu.18.00155

[13] Sayyed Z. J. and A. Hamne, "Seismic analysis of honeycomb structure over conventional structure with comparative study by using STAAD PRO," International Journal of Emerging Trends in Science and Technology, Vol. 4, No. 7, pp. 5343-5347, 2017.

[14] A. Vijayakumar and D. L. Venkatesh Babu, "Pushover analysis of existing reinforced concrete framed structures," European Journal of Scientific Research, Vol. 71, No. 2, pp. 195-202, Feb. 2012.

[15] S. Zerrinkorrkmaz, "An analytical study about the use of steel plate shear walls to improve lateral rigidity of reinforced concrete framed structures," Latin American Journal of Solids and Structures, Vol. 17, No. 7, 2020, https://doi.org/10.1590/1679-78256100

[16] Y. Zhang and X. Zhan, "Study on seismic behavior of steel frame-steel shear wall with assembled twoside connections," Mathematical Problems in Engineering, Vol. 2019, pp. 1-15, Dec. 2019, https://doi.org/10.1155/2019/3024912

[17] P. Huali, A.-A. Adedamola, M. Akbar, O. Guoqiang, and A. Amin, "The seismic analysis and performance of steel frame with additional low-yield-point steel dampers," Journal of Vibroengineering, Vol. 23, No. 3, pp. 647-674, May 2021, https://doi.org/10.21595/jve.2020.21531

[18] "GB 50017-2017. Standard for Design of Steel Structures," Ministry of Housing and Urban-Rural Development of PRC, National Standard of the People's Republic of China, 2017.

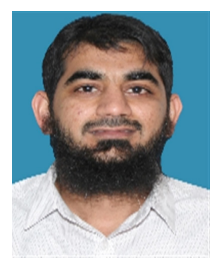

Muhammad Akbar Ph.D. student of geotechnical structures engineering and working in institute mountain hazard and environment. My current research interests include dynamics, control and mitigation of Structures. Author contributions: conceptualization and analysis, writing original draft, investigation.

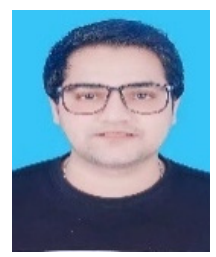

Assad Ali completed his degree in Master of civil engineering from Jiangsu University of Science and Technology, Jiangsu, China. Author contributions: methodology and software, visualization, data curation

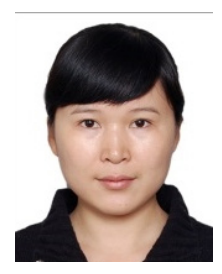

Pan Huali is a Professor of geotechnical engineering and working in the Institute Mountain Hazard and Environment, Chinese Academy of Sciences, Chengdu, China. She has a $\mathrm{Ph} . \mathrm{D}$. degree in engineering. Her current research interests include dynamics, control and mitigation of mountain hazards. Author contributions: supervision and project administration.

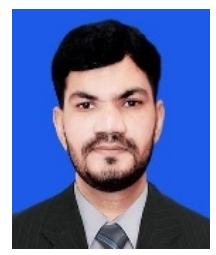

Muhammad Mohsin completed his degree in Master of civil engineering from Jiangsu University of Science and Technology, Jiangsu, China. Author contributions: writingreview and editing. 
SEISMIC ANALYSIS OF LATERAL FORCE RESISTING STEEL FRAME WITH HONEYCOMBED STEEL THIN PLATE SHEAR WALL. Muhammad Akbar, Assad Ali, Pan Huali, Muhammad Mohsin, Ou Guoqiang, Amin AzKa, Hazrat YousaF

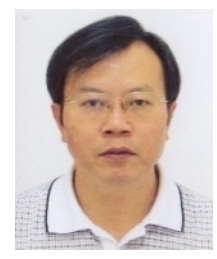

Ou Guoqiang is a Professor of geotechnical engineering and working in the Institute Mountain Hazard and Environment, Chinese Academy of Sciences, Chengdu, China. He has a post doctorate and $\mathrm{Ph} . \mathrm{D}$. degree in engineering. His current research interests include dynamics, control and mitigation of mountain hazards. Author contributions: supervision and project administration

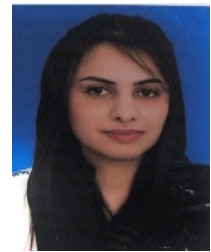

Azka Amin is a Professor and working in the Iqra Universit, Karachi, Pakistan. He has a post doctorate and Ph.D. degree. Author contributions: original draft preparation

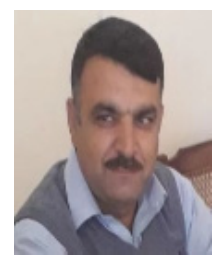

Hazrat Yousaf is a Professor and working in the Lasbela Universit, Pakistan. He has a Ph.D. degree. Author contributions: review and editing. 